\title{
Vertical Wind Profile Modeling at Low Levels Using a Regional Climate Model in a Case Study at the Alcântara Launch Center
}

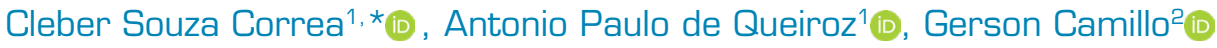

\begin{abstract}
1. Departamento de Ciência e Tecnologia Aeroespacial - Instituto de Aeronáutica e Espaço - Divisão de Ciências Atmosféricas São José dos Campos/São Paulo - Brazil 2. Universidade Federal de Santa Catarina - Faculdade de Computação - Departamento de Informática e Estatística - Florianópolis/Santa Catarina - Brazil.
\end{abstract}

*Corresponding author: cleber.voy@gmail.com

\begin{abstract}
This case study, using a regional climate model (RegCM-4.7) in high horizontal resolution, allowed to obtain information on the intensity of the average vertical wind profile over the Alcântara Launch Center (ALC), Brazil. In the literature, on the wind intensity, the lack of continuous monitoring of the existence of flows in the vertical profile of the wind at heights of 400 to $600 \mathrm{~m}$ and the measurement of its magnitude make it possible to have an estimate lower than what can occur in reality at a low level in the region for operational purposes for the rocket launch. Therefore, this works results points to an intraseasonal variability of the wind intensity with maximum winds of the order of 14 to $20 \mathrm{~m} \cdot \mathrm{s}^{-1}$ in the core wind intensity at heights of $600 \mathrm{~m}$, corresponding to pressure levels of the order of $930 \mathrm{hPa}$, in August, September and October 2020. These intensity values should be further studied with the use of observation equipment such as sound detection and ranging (SODAR) in the continuation of this research, in moment future, as well; the global models of reanalysis have low resolution and are not suitable for comparisons.
\end{abstract}

Keywords: Regional climate model; Sea-breeze circulations; Vertical wind profile.

\section{INTRODUCTION}

In space activities, a very important parameter of operational relevance is the vertical wind profile, which can affect the launching of rockets and could generate large deviations in the mission flight. The use of regional climatic models allows analyzing and generating simulations of a period with intraseasonal variability, allowing the estimation of predominant average parameters with circulation characteristics and wind intensity at low levels in the atmosphere. The use of climatic models can be an important tool to estimate atmospheric parameters, so the choice of domain and physical parameterization characteristics in high spatial resolution can influence the results.

An important aspect in climate modeling is the uncertainties involved in the simulations; some studies present and discuss this problem, such as Giorgi (2010), Vohland et al. (2014), Stagl et al. (2015) and Prein and Gobiet (2017). Climate models are important tools to estimate atmospheric parameters, so the choice of domain and physical parameterization schemes can influence the simulated results. In this context, some studies evaluate the sensitivity of climate models, such as Giorgi et al. (2012), Reboita et al. (2014), Souza et al. (2016), Ayar et al. (2016), Llopart et al. (2017), Pontoppidan et al. (2017) and Corrêa et al. (2018).

Received: Aug. 112020 | Accepted: Jan. 032021

Peer Review History: Double Blind Peer Review.

Section Editor: Willian Vaughan 
At the Alcântara Launch Center (ALC), a large number of investigations were carried out to estimate the characteristics which affect launch operations. Gisler et al. (2011) performed statistical studies with data from an anemometric tower and radiosonde at ALC. This study covered the period of 1995-1999 and analyzed the wind at six different levels: 6.0, 10.0, 16.3, 28.5, 43.0 and $70.0 \mathrm{~m}$. This analysis was done for typically rainy (March) and dry (September) seasons. The total data during the wet season (March) were 76,882 wind profiles (time interval of ten minutes) and during the dry season (September) were 109,809 profiles. The mean wind speed (or intensity) was computed along with standard deviation, median, mode and the prevailing wind direction. The predominant direction was Northeast (NE) with 33 and 40\% of the occurrences for wet and dry seasons, respectively. The average values of wind speed showed a dependency on height and it was observed that the highest levels of the anemometric tower have the strongest wind speed in the dry period $\left(8.2 \mathrm{~m} \cdot \mathrm{s}^{-1}\right)$. The average wind speeds observed were $6.4 \mathrm{~m} \cdot \mathrm{s}^{-1}$ for the dry season and $4.1 \mathrm{~m} \cdot \mathrm{s}^{-1}$ during the wet season.

Couto and Fisch (2014) analyzed the wind velocity at a height of $10 \mathrm{~m}$ between 2008 and 2010. These authors also carried out simulations with WRF3.6 to perform sensitivity tests and subsequently computed statistics between the model and the data observed during the period analyzed. This work also analyzed different physical parameters and spatial resolutions and no significant differences were observed between them.

Reuter et al. (2015) developed a study with the Pennsylvania State University/National Center for Atmospheric Research (PSU/NCAR) mesoscale model (MM5) intending to estimate meteorological parameters in the operation of the ALC, obtaining that the boundary layer parameterizations, using the medium-range forecast (MRF) and blackadar (BLK) parameterizations, the zonal and meridional wind components were underestimated by $16 \%$ in the rainy season and the average overestimated by $18 \%$ in the dry season.

Corrêa et al. (2017) used the RegCM4 model with a spatial resolution of $50 \mathrm{~km}$ to estimate the average vertical wind profile over five months, from August to December 2015, which observed intraseasonal variations, with predominant characteristics in the frequency direction (NE) and average wind intensity. The results were preliminary but present great potential, since they may show intraseasonal variations, which are important estimates that operationally affect rocket launching activities at ALC.

Due to the geographical characteristics of ALC, the presence of sea breezes on the coast, which can characterize more intense winds close to the surface, in the study by Silva and Corrêa (2019) using radiosonde data and a multivariate statistical technique from the principal components analysis (PCA), it could characterize the existence of low-level jets (LLJ) and flows at different heights close to the surface. Corrêa et al. (2019) used simulations carried out by the National Centers for Environmental Prediction (NCEP) coupled forecasting model version 2 (CFSv2)/regional climate model RegCM-4.6, the data analyzed were the information of the surface wind intensity through the analysis and comparison of the simulations carried out for the Alcântara region, on the coast of the state of Maranhão.

The analysis sought to validate with the ERA5 reanalysis data from the European Center for Medium-Term Meteorological Forecasts (ECMWF). The observed result shows great potential for using ensemble prediction techniques, since in the observed results the smallest anomalies were observed in the intraseasonal ensemble prediction for the Alcântara region in the wind intensity, in comparison with the simulation without an ensemble, showing greater deviations and when closer to the forecast itself, greater deviations presented. The intraseasonal ensemble estimate ends up filtering the high-frequency terms, being the best estimate, and presenting more balanced intraseasonal forecasts.

The use of regional climate modeling in high spatial resolution may not be able to observe the entire non-linearity structure associated with the vertical wind profile, but it can help to show certain average characteristics associated with the vertical wind profile. As well as estimate values of wind intensity at heights, when they do not have high-resolution measurement instruments or that are out of the measurement range. Therefore, in the literature, there are no estimates of the maximum intensities of the vertical wind profile close to the surface in the ALC, at heights of the order of 200 to $800 \mathrm{~m}$, which can be associated with the seabreeze mechanism and even maintain an LLJ structure. The study is justified by the need to use regional models in high spatial horizontal resolution and, consequently, obtain average characteristics of the vertical wind profile and the possible intraseasonal variability in the ALC, with a focus on rocket launching. 


\section{METHODOLOGY}

This work uses the climate forecast system version 2 (CFSv2) operational forecasts data, which is operated by the NCEP (Saha et al. 2014), as the initial and boundary condition from RegCM4.7 (Giorgi et al. 2012; 2015). The community land model (CLM) model version 4.5 was also used (Oleson et al. 2008), which is the land surface model developed by the National Center of Atmospheric Research (NCAR) as part of the community climate system model (CCSM), described in detail in Collins et al. (2006). This work aims to analyze the simulations of the CFSv2/RegCM4.7 stored model, between July 15 and November 02 , 2020, when it was operationalized in the atmospheric sciences division of the Instituto de Aeronáutica e Espaço (IAE), Intraer link (http://www.iae.cta.intraer/cfs/), which products are available for use in intraseasonal forecasts of the vertical wind profile at the ALC.

Table 1 shows the configurations and parameterizations used in the three simulations performed, seeking to use a strategy of using high spatial resolutions to obtain and observe in the resulting simulation vertical characteristics of the wind intensity close to the surface.

Table 1. Parameters used in Physics ParamNameList (regcm.in) in RegCM4.7 model.

\begin{tabular}{|c|c|}
\hline Parameter & Value \\
\hline Lateral boundary conditions scheme & $\begin{array}{l}\text { Relaxation, exponential technique, Marbaix et al. } \\
\text { (2003] }\end{array}$ \\
\hline Planetary boundary layer (PBL) scheme & Holtslag PBL, Holtslag et al. (1990) \\
\hline \multicolumn{2}{|l|}{ Cumulus convection schemes } \\
\hline Over land & Grell (1993) \\
\hline Over ocean & Emanuel (1991) \\
\hline Moisture scheme & Explicit moisture [SUBEX, Pal et al. (2000)] \\
\hline Ocean flux scheme & Zeng et al. (1998) \\
\hline Zeng ocean model roughness formula to used & 1- > [0.0065* ustar *ustar $]$ /egrav \\
\hline Calendar & Gregorian \\
\hline Globdatparam ssttyp & CFSO1 \\
\hline Globdatparam dattyp & CFSO1 \\
\hline Land surface model & CLM4.5 \\
\hline $100 \times 120$ grid points & $25 \mathrm{~km}$ horizontal resolution \\
\hline $160 \times 180$ grid points & $15 \mathrm{~km}$ horizontal resolution \\
\hline $180 \times 212$ grid points & $10 \mathrm{~km}$ horizontal resolution \\
\hline
\end{tabular}

The domains are centered at the ALC in Maranhão state in latitude - 02.0 and longitude -43.0 approximately. For the post-processing of the result, analyzes of the average vertical wind profile of the simulated wind intensity are generated through vertical cuts in time for a monthly period, using figures generated in the Grid Analysis and Display System (GrADS) software available on the internet (http://cola.gmu.edu/grads/).

Figure 1 shows small details and differences between domains 2 and 3, which can be seen in the observed results of the simulations with the RegCM-4.7/CFSv2 model with 23 vertical levels. In this work, the number of vertical levels was not changed using the model default. However, the development of the regional climate model (RegCM-4.7) with the closing of parameters and the physical representation of processes makes the model a reference in the state of the art at this time, around $10 \mathrm{~km}$ of spatial resolution. The increase in the horizontal resolution allows representing more realistically the physical phenomena close to the surface because of the regional climate model, increasing its description of the horizontal domain. After all, it allows to represent a system of differential equations over a domain that obeys the uniqueness of the solution theorem because it has only one solution and it also obeys the conservation of energy and mass when closing numerical equations. 

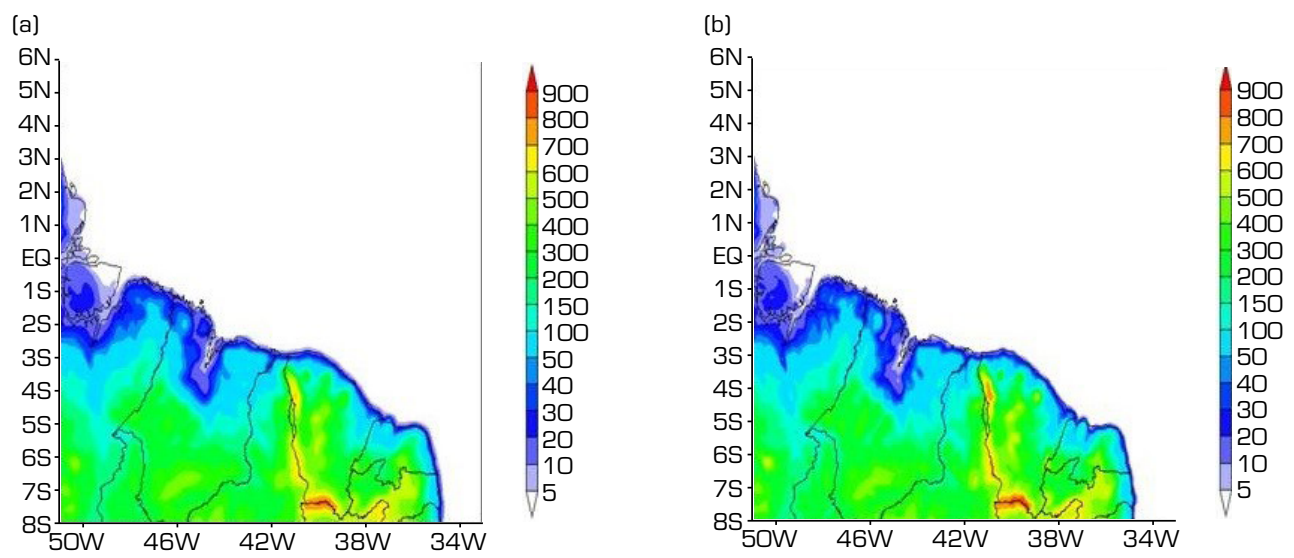

Figure 1. The topography (meters) and the domain used in the test simulations of RegCM4.7 with CFSv2, with the geographic center on the ALC. The geographical location of the ALC is marked with a black dot. Presenting (a) - domains 2 with resolutions of $160 \times 180$ grid points and $15 \mathrm{~km}$ horizontal resolution and (b) - domains 3 with $180 \times 212$ grid points and $10 \mathrm{~km}$ horizontal resolution.

For the same period, the ERA5 reanalyzes the global model of the ECMWF, Copernicus Climate Change Service (C3S 2017), which is using comparatively the months of August, September and October 2020. The variables analyzed were $u$ and $v$ from the ERA5 dataset hourly data on pressure levels from 1979 to present (https://cds.climate.copernicus.eu/cdsapp\#!/dataset/reanalysisera5-pressure-levels?tab=form). The information was analyzed using graphs generated by Grads.

The ERA5 is produced using 4D-Var data assimilation in CY41R2 of ECMWF integrated forecast system (IFS), with 137 hybrid sigma/pressure (model) levels in the vertical, with the top-level at $0.01 \mathrm{hPa}$. Atmospheric data are available on these levels and they are also interpolated to 37 pressure, 16 potential temperature and one potential vorticity level (s). Surface or single level data are also available, containing $2 \mathrm{D}$ parameters such as precipitation, $2 \mathrm{~m}$ temperature, top of atmosphere radiation and vertical integrals over the entire atmosphere. The ERA5 dataset contains one (hourly, $31 \mathrm{~km}$ ) high-resolution realization (referred to as reanalysis or HRES) and a reduced resolution ten-member ensemble (referred to as ensemble or EDA). The information from the global ERA5 model was used for the latitude and longitude of the ALC.

\section{RESULTS}

The structure of the vertical wind profile with an ocean breeze close to the surface presents a very complex vertical structure and specific characteristics as example. Its thickness is thin with tens of meters and its occurrence in periods of three to five days, therefore for its observation to continue it must be done by remote sensing equipment, such as wind profiler, which is a type of weather observing equipment that uses radar or sound waves (SODAR) to detect the wind speed and direction. Another type that can also be used is the light detection and ranging (Lider), it is an optical remote sensing technology that measures reflected light properties. At the ALC, it was observed utilizing radiosondes at night and in the morning. Silva and Corrêa (2019) could observe flows in the vertical wind profile, these flows would characterize local circulations and were associated with sea-breeze circulations and regionally characterize circulations at the synoptic mesoscale level, such as LLJ.

The results for the study period, from July 1 to November 30, 2014, show the presence of the LLJ-weak type, LLJ-0 and LLJ-1, classification of LLJ proposed by Corrêa et al. (2001), with $85 \%$ of the variance explained in the first, second and third components in the night period. The first component with a height of $800 \mathrm{~m}$ (average direction 60 to $70^{\circ}$ and with a magnitude greater than $10 \mathrm{~m} \cdot \mathrm{s}^{-1}$ and shear of the order of $5 \mathrm{~m} \cdot \mathrm{s}^{-1}$ ), the second component with a height of $400 \mathrm{~m}$ (average direction 40 to $50^{\circ}$ and with a magnitude of approximately $9 \mathrm{~m} \cdot \mathrm{s}^{-1}$, shear on the order of $5 \mathrm{~m} \cdot \mathrm{s}^{-1}$ ) and the third component with $200 \mathrm{~m}$ (direction average 50 to $60^{\circ}$ and with a magnitude greater than $7 \mathrm{~m} \cdot \mathrm{s}^{-1}$ and shear of the order of $5 \mathrm{~m} \cdot \mathrm{s}^{-1}$ ). This characteristic can be associated with a complex dynamic response of different associated meteorological synoptic scales, the average wind associated with the sea-breeze, in the case 
of the highest height $(800 \mathrm{~m})$ and the lowest height of the order of $200 \mathrm{~m}$ with processes associated with the planetary boundary layer (PBL) in the night period, as the inversion maximum wind and sea-breeze. Therefore, the vertical profile of the wind close to the surface presents a complex and non-linear structure, in a complex physical response to the mechanisms that created them.

Figure 2 shows the simulations performed with different domains and spatial resolutions. The results are important because they show that the increase in spatial resolution of the model improves the observation of flows at low levels, with a better definition of intensities and heights about the surface of these flows. The result shows that, at the end of August 2020 and the beginning of September, it presents an intensity cycle of the average vertical wind profile in ALC. It also shows that the maximum winds in the vertical profile are grouped in groups of three to five days. The complexity is great, and physically, these represent nonlinear relationships associated with the turbulence and synoptic processes close to the surface at low levels. The regional climate model can be used to simulate intraseasonal time scales and to observe maximum structures in the wind intensity close to the surface in the three-month time scale.
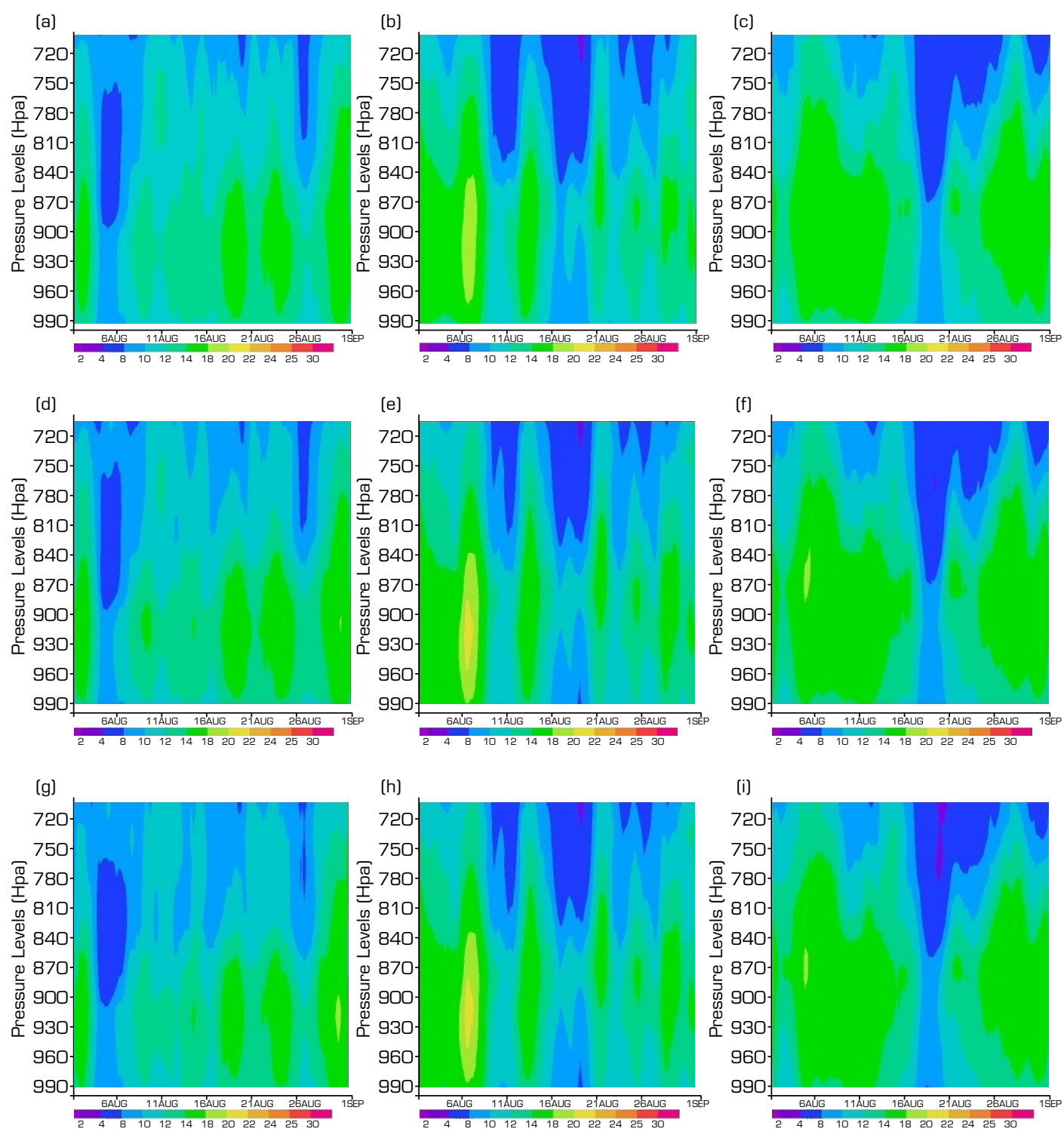

Figure 2. The vertical section of the average vertical wind profile over time over ALC is in meters per second. Domain 1 - (a) August 2020, (b) September 2020 and (c) October 2020, with $25 \mathrm{~km}$ horizontal resolution.

Domain 2 - (d) August 2020, (e) September 2020 and (f) October 2020, with $15 \mathrm{~km}$ horizontal resolution.

Domain 3 - (g) August 2020, (h) September 2020 and (i) October 2020, with $10 \mathrm{~km}$ with horizontal resolution. 
Figures 2a, d and g, month of August 2020, show periods with wind speeds of the order of $14 \mathrm{~m} \cdot \mathrm{s}^{-1}$, in the pressure levels of the order of 960 to $870 \mathrm{hPa}$ with a more intense core at the level of 930 to $900 \mathrm{hPa}$. Figures $2 \mathrm{~b}$, e and h, the month of September 2020 , show periods with wind speeds of the order of $20 \mathrm{~m} \cdot \mathrm{s}^{-1}$ with a more intense core at the level of $930 \mathrm{hPa}$, in the pressure levels of the order of 980 to $840 \mathrm{hPa}$. Figure 2c, f, and i, the month of October 2020, the intensity of the wind decreases with a maximum core of $870 \mathrm{hPa}$ and wind speeds of the order of $14 \mathrm{~m} \cdot \mathrm{s}^{-1}$. The pressure levels in the order of $930 \mathrm{hPa}$ correspond to a physical height in the order of 600 meters in the ALC. Such results show an intraseasonal variability in wind intensity at low levels and the results are consistent with the work of Silva and Corrêa (2019).

The simulations were important because they show results associated with the observations of radiosondes. However, the model used in this case study does not have adequate vertical resolution details, but a high horizontal resolution was used, which does not allow the regional model to separate the levels vertically with greater precision.

Figure 3 shows the vertical wind profile over the ALC, can be seen in the ERA5 reanalysis is that it maintains a profile intensity indicator at the height of 930 to $960 \mathrm{hPa}$ corresponding to the height below $600 \mathrm{~m}$. Although the reanalysis has a low resolution of $31 \mathrm{~km}$, speeds of $14 \mathrm{~m} \cdot \mathrm{s}^{-1}$ and small ones of $20 \mathrm{~m} \cdot \mathrm{s}^{-1}$ can be observed in August and September 2020. These characteristics allow underestimating the nature of the flows associated with the breeze phenomenon in Alcântara, the CFS/RegCM-4.7 in high resolution presents more information that must be confirmed in future works, using information from the vertical wind profile obtained with the SODAR.
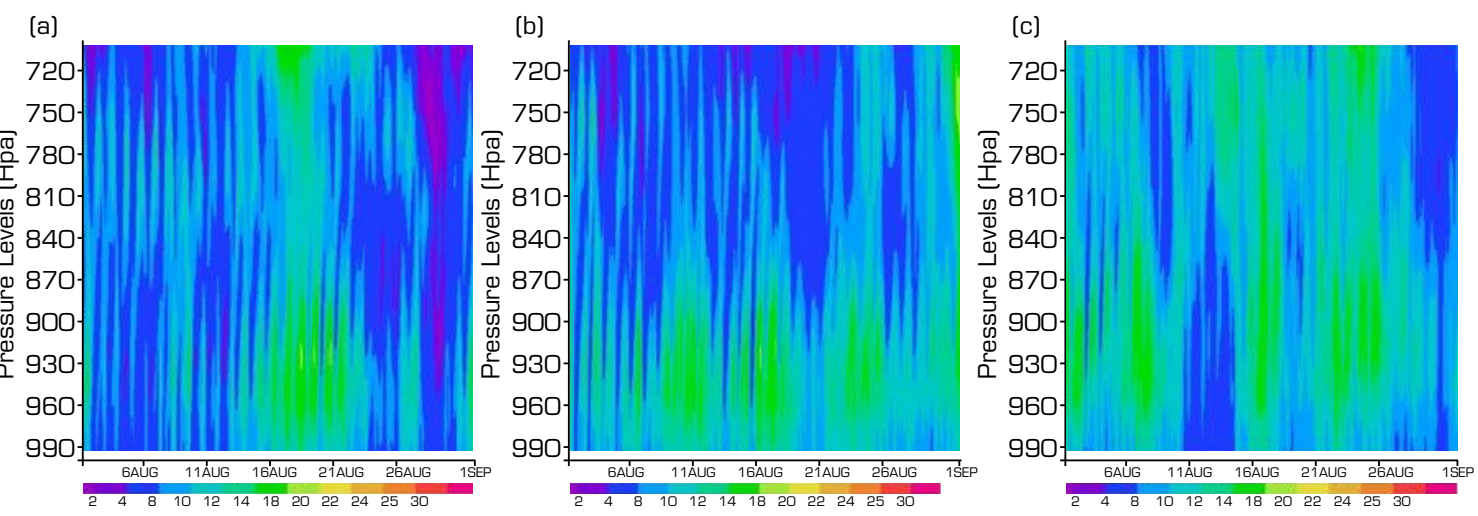

Figure 3. The vertical section of the vertical wind profile over time over ALC, shows the ERA5 Reanalysis global model of the European Center for Medium-Range Weather Forecasts (ECMWF) on which the vertical wind profile information (u,v) dataset hourly data on pressure levels, (a) August 2020, (b) September 2020 and

(c) October 2020, with $31 \mathrm{~km}$ horizontal resolution, the vertical wind profile is in meters per second.

\section{CONCLUSIONS}

This work shows an intensity estimate of the vertical wind profile in Alcântara, order intensities of 14 to $20 \mathrm{~m} \cdot \mathrm{s}^{-1}$, and shows intraseasonal variability in the studied period. It also shows that the regional climate model can make estimates of wind intensity by making intraseasonal forecasts. The increase in horizontal resolution showed that qualitatively more information on the simulated vertical wind profile compared to the low horizontal resolution of ERA5 reanalysis. More research will be developed in more detail in the observation of the vertical wind profile with the SODAR equipment, which may generate more detailed results of the breeze phenomenon in Alcântara. The regional climatic model had a significant improvement in representing the wind intensity processes with the increase in resolution horizontal. However, the increase in vertical levels of the model was not used in this work, which will be carried out in future researches, as well as the use of continuous monitoring equipment at the ALC. 


\section{AUTHORS' CONTRIBUTION}

Conceptualization: Correa CS; Queiroz AP and Camillo G; Formal analysis: Correa CS; Queiroz AP and Camillo G; Writing - Original Draft: Correa CS; Queiroz AP and Camillo G; Writing - Review \& Editing: Correa CS and Queiroz AP; Supervision: Correa CS; Queiroz AP and Camillo G.

\section{DATA AVAILABILITY STATEMENT}

The data developed in this work can be made available upon request.

\section{FUNDING}

Not applicable.

\section{ACKNOWLEDGEMENTS}

The authors acknowledge the assistance of the Instituto de Aeronáutica e Espaço (IAE).

\section{REFERENCES}

[C3S] Copernicus Climate Change Service (2017) ERA5: Fifth generation of ECMWF atmospheric reanalyses of the global climate. Copernicus Climate Change Service Climate Data Store (CDS). [accessed Nov 08 2020] https://cds.climate. copernicus.eu/cdsapp\#!/home

Ayar PV, Vrac M, Bastin S, Carreau J, Déqué M, Gallardo C (2016) Intercomparison of statistical and dynamical downscaling models under the EURO- and MED-CORDEX initiative framework: present climate evaluations. Clim Dyn 46(3-4):13011329. https://doi.org/10.1007/s00382-015-2647-5

Collins WD, Bitz CM, Blackmon ML, Bonan GB, Bretherton CS, Carton JA, Chang P, Doney SC, Hack JJ, Henderson TB, et al. (2006) The Community Climate System Model Version 3 (CCSM3). J Clim 19(1):2122-2143. https://doi.org/10.1175/ JCLI3761.1

Corrêa CS, Dallarosa RLG, Degrazia, GA (2001) Estudo Observacional dos Jatos de Nível Baixo Sobre a Região Metropolitana de Porto Alegre. Rev Bras de Recur Hidr 6(4):19-27. https://doi.org/10.21168/rbrh.v6n4.p19-27

Corrêa CS, Camillo GL, Couto VM, Fisch G, Corrêa FN, Härter F (2017) Climate forecasts at the Centro de Lançamento de Alcântara using the climate model RegCM4. J. Aerosp Technol Manag 9(1):18-28. https://doi.org/10.5028/jatm.v9i1.649

Corrêa CS, Reibota MS, Camillo GL, Couto VM, Corrêa FN (2018) Intraseasonal climate forecast for the Alcântara region in Northeastern Brazil. Revista Brasileira de Geografia Física. 11(6):1963-1970. https://doi.org/10.26848/rbgf.v11.6.p1963-1970

Corrêa CS, Harter FP, Camillo GL (2019) Intraseasonal Ensemble Forecasting for the Brazilian Northeastern. Ci e Nat 41(e10):1-8. https://doi.org/10.5902/2179460X35807 
Couto VM, Fisch GF (2014) Testes de sensibilidade no CLA utilizando WRF3.6. Paper presented XVIII Congresso Brasileiro de Meteorologia (XVIII CBMET). Recife, Brazil.

Emanuel KA (1991) A Scheme for Representing Cumulus Convection in Large-Scale Models. J Atmos Sci 48(21):2313-2329. https://doi.org/10.1175/1520-0469(1991)048<2313:ASFRCC>2.0.CO;2

Giorgi F (2010) Uncertainties in climate change projections, from the global to the regional scale. In EPJ Web Conf 9:115129. https://doi.org/10.1051/epjconf/201009009

Giorgi F, Coppola E, Solmon F, Mariotti L, Sylla MB, Bi X, Elguindi N, Diro GT, Nair V, Giuliani G, et al. (2012) RegCM4: model description and preliminary tests over multiple CORDEX domains. Clim Res 52:7-29. https://doi.org/10.3354/cr01018

Giorgi F, Elguindi N, Cozzini S, Solmon F (2015) Regional Climatic Model RegCM User’s Guide Version 4.4.

Gisler CAF, Fisch G, Corrêa CS (2011) Statistical Analysis of Wind Profile in The Surface Layer at the Alcântara Launching Center. J Aerosp Technol Manag 3(2):193-202. https://doi.org/10.5028/jatm.2011.03022411

Grell GA (1993) Prognostic Evaluation of Assumptions Used by Cumulus Parameterizations. Mon Weather Rev 121(3):764787. https://doi.org/10.1175/1520-0493(1993)121<0764:PEOAUB>2.0.CO;2

Holtslag AAM, De Bruijn EIF, Pan H-L (1990) A High Resolution Air Mass Transformation Model for Short-Range Weather Forecasting. Mon Weather Rev 118(8):1561-1575. https://doi.org/10.1175/1520-0493(1990)118<1561:AHRAMT>2.0.CO;2

Llopart M., Rocha RP, Reboita M, Cuadra S (2017) Sensitivity of simulated South America climate to the land surface schemes in RegCM 4 . Clim Dyn 49(11-12):3975-3987. https://doi.org/10.1007/s00382-017-3557-5

Marbaix P, Gallee H, Brasseur O, Van Ypersele JP. (2003) Lateral boundary conditions in regional climate models: a detailed study of the relaxation procedure. Mon Weather Rev 131(3):461-479. https://doi.org/10.1175/1520-0493(2003)131<0461:LB CIRC $>2.0 . \mathrm{CO} ; 2$

Oleson KW, Niu G-Y, Yang Z-L, Lawrence DM, Thornton PE, Lawrence PJ, Stöckli, R, Dickinson RE, Bonan GB, Levis S, Dai A, Qian ADT (2008) Improvements to the Community Land Model and their impact on the hydrological cycle. J Geophys Res Earth Surf 113(G1). https://doi.org/10.1029/2007JG000563

Pal JS, Small EE, Eltahir EAB (2000) Simulation of regional-scale water and energy budgets- Representation of subgrid cloud and precipitation processes within RegCM. J Geophys Res Atmos 105(D24):29579-29594. https://doi.org/10.1029/2000JD900415

Pontoppidan M, Reuder J, Mayer S, Kolstad EW (2017). Downscaling an intense precipitation event in complex terrain: the importance of high grid resolution. Tellus A: Dynamic Meteorology and Oceanography 69(1):1271561. https://doi.org/10.1 $080 / 16000870.2016 .1271561$

Prein AF, Gobiet A (2017) Impacts of uncertainties in European gridded precipitation observations on regional climate analysis. Int J Climatol 37(1):305-327. https://doi.org/10.1002/joc.4706

Reboita MS, Fernandez JPR, Llopart MP, Rocha RP, Pampuch LA, Cruz FT (2014) Assessment of RegCM4.3 over the CORDEX South America domain: sensitivity analysis for physical parameterization schemes. Clim Res 60(3):215-234. https://doi.org/10.3354/cr01239

Reuter EDJ, Fisch G, Corrêa CS (2015) The sensitivity of wind forecasts with a mesoscale meteorological model at the Centro de Lançamento de Alcântara. J Aerosp Technol Manag 7(2):247-258. https://doi.org/10.5028/jatm.v7i2.388

Saha S, Moorthi S, Wu X, Wang J, Nadiga S, Tripp P, Behringer D, Hou Y-T, Chuang H-Y, Iredell M, et al. (2014) The NCEP Climate Forecast System Version 2. J Clim 27(6):2185-2208. https://doi.org/10.1175/JCLI-D-12-00823.1 
Silva PN, Corrêa CS (2019) Analysis of the vertical wind profile at the Alcântara Launch Center using principal components analysis. Ci e Nat 41(e11):1-8. https://doi.org/10.5902/2179460X33041

Souza EB, Carmo AMC, Moares BC, Nacif A, Ferreira DBS, Rocha EJP, Souza, PJOP (2016) Sazonalidade da Precipitação Sobre a Amazônia Legal Brasileira: Clima Atual e Projeções Futuras Usando o Modelo RegCM4. RBCLima 18:293-306. https://doi.org/10.5380/abclima.v18i0.43711

Stagl J, Hattermann FF, Vohland K (2015 Exposure to climate change in Central Europe: What can be gained from regional climate projections for management decisions of protected areas? Reg Environ Change 15(7):1409-1419. https://doi. org/10.1007/s10113-014-0704-y

Vohland K, Rannow S, Stagl J (2014) Climate Change Impact Modelling Cascade-Benefits and Limitations for Conservation Management. In Rannow W, Neubert M, editors. Managing Protected Areas in Central and Eastern Europe Under Climate Change. Dordrecht: Springer. p. 63-76. https://doi.org/10.1007/978-94-007-7960-0_5

Zeng X, Zhao M, Dickinson RE (1998) Intercomparison of Bulk Aerodynamic Algorithms for the Computation of Sea Surface Fluxes Using TOGA COARE and TAO Data. J Clim 11(10):2628-2644. https://doi.org/10.1175/1520-0442(1998)011<2628:IO $\mathrm{BAAF}>2.0 . \mathrm{CO} ; 2$ 